\title{
IMAGINÁRIOS DO(S) DESLOCAMENTO(S) NA CONTEMPORANEIDADE: REPRESENTAÇÕES DOS SUJEITOS EM TRÂNSITO.
}

\author{
Rodrigo de Freitas Faqueri ${ }^{1}$ \\ ORCID: https://orcid.org/0000-0002-9292-3536
}

Daniele Aparecida Pereira Zaratin ${ }^{2}$

ORCID: https://orcid.org/0000-0001-8236-4227?lang=pt

O tema dos deslocamentos tem sido um dos eixos narrativos fundamentais das produções literárias ao longo dos tempos. Ao pensar sobre as suas formas, Edward Said, em seu Reflexões sobre o exílio e outros ensaios (2003), propõe algumas distinções. Segundo o autor, há os sujeitos exilados, refugiados, expatriados e emigrados. Os primeiros se relacionam ao desenraizamento forçado, o que provoca no banido, quase sempre, o sentimento de infelicidade; os segundos "são uma criação do Estado do século XX" e trazem uma imagem de pessoas sem rumo, necessitadas da "ajuda internacional urgente", afirma Said (2003, p. 35); já os expatriados e emigrados compartilham semelhanças e se relacionam, ainda de acordo com o teórico, aos sujeitos que partem voluntariamente para outros países, seja por motivações sociais e/ou econômicas.

Nas últimas décadas, pode-se observar uma multiplicidade de obras ficcionais cujos enredos trazem uma pluralidade de formas de deslocamentos a partir de trajetórias de personagens, as quais, ao entrar em contato com a alteridade, seja em contextos eufóricos eou disfóricos, ressignificam a sua própria concepção de identidade(s) por meio de deslocamentos simbólicos.

\footnotetext{
${ }^{1}$ Doutor em Letras pela Universidade Presbiteriana Mackenzie. Professor EBTT - Português/Espanhol e Diretor Adjunto Educacional do IFSP-Campus Itaquaquecetuba. Docente colaborador do GT "Vertentes do Insólito Ficcional" (ANPOLL). Possui pesquisas nas áreas de literaturas de língua portuguesa e espanhola e estudos culturais, centrando sua análise na temática da violência e suas representações literárias. E-mail de contato: rodrigofaqueri@ifsp.edu.br

${ }^{2}$ Doutora em Letras pela Universidade Presbiteriana Mackenzie, professora no IFSP e pesquisadora-docente colaboradora do GT "Vertentes do Insólito Ficcional" (ANPOLL). Suas pesquisas se centram na literatura latino-americana, sobretudo na produzida durante os séculos XX e XXI nos países de língua espanhola. E-mail de contato: daniele_zaratin@yahoo.com.br
} 
Levando em consideração essas questões e tendo em vista os estudos de E. Said, S. Hall, N. García Canclini, M. Augé, T. Todorov, entre outros, este dossiê da Revista Téssera buscou reunir textos que tratassem das múltiplas representações de deslocamentos em obras literárias contemporâneas, sejam elas nacionais ou estrangeiras.

Em “Metáforas da nação e a experiência migrante em 'Luanda', 'Lisboa', 'Paraíso' e 'Também os brancos sabem dançar", artigo escrito por Adriano Carlos Moura, o leitor encontra uma análise fundamentada dessas obras dos angolanos Djaimilia Pereira de Almeida e de Kalaf Epalanga a partir do conceito de metáfora de nação. Baseado no que postula Segismundo Spina (2010) sobre metáfora "ascendente" e “descendente", o pesquisador destaca: “A metáfora da nação é uma espécie de metáfora impura, ou seja, carrega vestígio do real diferente da metáfora pura, totalmente desprovida de qualquer vínculo com o mundo denotado". A partir disso e da ideia de que o "romance cuja protagonista é a nação pode ser lido como expressão dessa coletividade”, o artigo de Adriano Carlos Moura conclui que "Sujeitos sem-estado, como Cartola e Aquiles, continuam sendo produzidos aos milhares. [...] Embora os romances aqui estudados sejam centrados na experiência de indivíduos, as questões que problematizam são da ordem da coletividade, visto que as peripécias que desenvolvem seus enredos nas tramas da ficção são comuns no mundo empírico espelhado."

Em “'Cidadã de segunda classe': sujeitos femininos e a fragmentação identitária no mundo pós-colonial”, Maria Isabel Lemos analisa na obra da nigeriana Buchi Emecheta uma pluralidade de deslocamentos e alteridades. A pesquisadora também reflete sobre como se dá a experiência de fragmentação e transmutação identitária vivenciada por migrantes, indicando, ainda, quais seriam as suas consequências na contemporaneidade. Nesse sentido, Maria Isabel destaca o "deslocamento geográfico e sua dimensão imaterial” na obra e ressalta que, por meio da análise da trajetória e das experiências da personagem Adah Obi, verifica-se uma "constante reconstrução identitária [...] e as complexidades dialéticas dos múltiplos processos identitários [...] a partir das fragmentadas categorizações sociais de gênero, raça, etnia, classe social e profissional em um contexto pós-colonial."

Já em "Um romance não escrito, uma viagem não realizada: Roland Barthes por Paloma Vidal, em 'Não escrever'”, a pesquisadora Katerina Blasques Kaspar analisa a figura de Roland Barthes a partir de diferentes perspectivas: seja enquanto personagem, como intelectual ou sujeito biográfico. Após seu percurso investigativo, a Katerina Blasques 
constata que se pode notar na obra de Paloma Vidal "uma insistência no deslocamento geográfico" e uma "prática literária contemporânea [...] de constituir narrativas descontínuas". Com isso, afirma a pesquisadora, por meio desse projeto que extrapola o plural seja pelas "vias da escrita de si e da autoficção", a escritora Paloma Vidal "parece convidar seus leitores a uma certa deriva, levando-os por caminhos conectados, avizinhados."

“Metamorfoses: deslocamento e pertencimento em 'Tudo são histórias de amor', de Dulce Maria Cardoso" é o seguinte artigo que compõe este dossiê. Neste estudo, Larissa Fonseca e Silva propõe uma leitura da obra da autora portuguesa, que segundo a pesquisadora, consiste em um "conto com diversos fragmentos dos mais diversos discursos e com uma narradora marcada pela multiplicidade”. Nesse sentido,

a partir da compreensão de que as diversas camadas textuais possibilitam o vislumbre do processo de (re)construção do sujeito que narra, a referida análise permite ao leitor verificar um "processo metamórfico, simbólico, polifônico e autoficcional", no qual encontra-se um “[...] sujeito fragmentado, deslocado e descentralizado (HUTCHEON, 1991; SAID, 2004; HALL, 2006)."

O artigo de Maria Letícia Macêdo Bezerra, intitulado "Maryse Condé e a África no horizonte", apresenta um estudo sobre o deslocamento da escritora guadalupense Maryse Condé à África, tomando como objeto literário duas autobiografias da autora: Le coeur à rire et à pleurer (1999) e La vie sans fards (2012). A autora deste artigo apresenta uma análise sobre o deslocamento não só físico e espacial, por conta das diásporas negras, mas também afetivo e identitário, ancorado em estudos que versam sobre o anticolonialismo e o movimento da negritude. Em seu texto, Bezerra afirma que "enquanto a África era um destino turístico [...], para Condé representava um enigma que sempre the trouxe inquietação. As Antilhas perdem o seu significado para a escritora ao ser reduzida a um símbolo de alienação, e, assim, é para o externo que o seu interesse se desloca."

Em “Todos os rios levam a sua boca: migração e poesia em José Leonilson”, Marina Baltazar Mattos e Gustavo Silveira Ribeiro nos convidam para mergulhar em uma viagem no nomadismo de José Leonilson, artista cearense. Em um constante movimento afetivo, corporal e geográfico/espacial, é apresentada a obra desse artista que insiste e persiste em ser um cidadão do mundo com sua arte profunda. Tendo os quatro pontos cardeais como rumo e parâmetro de deslocamento recorrente, de acordo com os autores, “[...] Leonilson 
escreveu e se inscreveu no mundo: seu Norte é sua arte, seu direito e seu avesso, seu ponto de cruz em palavra e saudade, entre a verdade e a ficção, em signos que seguem ressoando e nos convidando a preparar nossa bússola para a viagem".

Já o texto de Pietro Gabriel dos Santos Pacheco e Leonardo von Pfeil Romme nos leva para o processo de representação da memória e da identidade na obra Até que as pedras se tornem mais leves que a água (2017), do aclamado português António Lobo Antunes. Sob o título "O lembrar e o esquecer: memória e identidade em Até que as pedras se tornem mais leves que a água, de Lobo Antunes", os autores apresentam uma análise preciosa sobre as tensões retratadas na obra portuguesa, provenientes do embate entre colonizado e colonizador e dos traumas que essa relação conflituosa criou. Atrelados a isso, estão a memória e a identidade fragmentada de ambos os lados, seja do colonizado, seja do colonizador. Sobre a identidade e uma suposta ideia de completude, os autores ponderam que "ser ou não ser não é se tornar completo, mas entender quem ou o que se é naquele momento, principalmente através das imposições realizadas desde os primeiros momentos de nossa trajetória. A identidade é construída ao longo da vida, balizada pelas ações e pelo meio onde o homem está inserido. Ser ou não ser é a prova de que o indivíduo nunca está pronto e o processo nunca será terminado." Sobre o romance de Lobo Antunes analisado, Pacheco e Romme apontam que “ (...) o passado colonial ainda não está encerrado e habita, mesmo que de forma espectral, a consciência do Portugal contemporâneo através de figuras como o filho preto, que representa todos os exilados pela brutalidade da Guerra e do colonialismo europeu."

No artigo "O aterrorizante feminino: uma simbólica da mulher enquanto agente desviante", de Camila Pordeus, encontramos uma sólida análise sobre a construção imagética do corpo feminino a partir da representação contemporânea do imaginário míticosimbólico. Neste estudo, são suscitadas diversas discussões sobre a figura feminina e quais as significações atreladas a esse imaginário arquetípico. Em uma extensa análise, que mescla observações sobre produções artísticas de diferentes vertentes (como pinturas e filmes) com grande arcabouço teórico, a autora indica as representações simbólicas do corpo feminino: aquele que sangra, o que representa o mal, a feiura e a beleza; simboliza o início e o fim de um ciclo: “[...] as relações de simbolismo que envolvem a mística feminina [e] fazem parte do conjunto que Eliade chamou de símbolos lunares. [...] A lua é ao mesmo tempo morte lua nova - e renascimento - lua crescente - uma relação parecida com : "atraído pela mulher, 
o outro sexo é do mesmo modo repelido pelo fluxo menstrual, pelos odores, pelas secreções de sua parceira, pelo líquido amniótico, pelas expulsões do parto" (DELUMEAU, 2009, p. 464)."

Por fim, na resenha escrita por Analice de Oliveira Martins, intitulada "Geografias do afeto e do desterro", podemos encontrar uma leitura crítica sobre Deriva (2019), obra poética de Adriana Lisboa. De acordo com Analice de Oliveira, neste livro "há, em Deriva, três situações bem delineadas e também entrelaçadas de deslocamento ou de trânsito: a social, a lírico-amorosa e a artística. Quanto ao aspecto social, a condição estrangeira, migrante, à margem da sociedade, constitui uma voz enunciativa recorrente em vários poemas, transcendendo o aspecto intimista e olhando ao redor, ao redor do mundo.”

Com este dossiê, a Revista Téssera mantém sua tendência em contribuir com os estudos mais atuais sobre o imaginário e as representações literárias, assim como colabora para ampliar as reflexões sobre os deslocamentos culturais, solidificando-se como referência no debate sobre os temas mencionados. Nesse sentido, os autores deste número propuseram diversas discussões que confluem para um pensamento constante e necessário sobre as representações do imaginário e do deslocamento, reiterando a atualidade do dossiê proposto. Boa leitura!

\section{Referências}

AUGÉ, Marc. Não-lugares: Introdução a uma antropologia da supermodernidade. Trad. Maria Lúcia Pereira. Campinas: Papirus Editora, 2013.

GARCÍA CANCLINI, Nestor. Culturas Híbridas: Estratégias para entrar e sair da modernidade. Trad. Heloísa Pezza Cintrão, Ana Regina Lessa, Gênese Andrade. São Paulo: EDUSP, 2008.

HALL, Stuart. Da diáspora: Identidades e mediações culturais. Org. Liv Sovik. Trad. Adelaide La Guardia Resende et al. Belo Horizonte: Ed. UFMG, 2009.

SAID, Edward. Reflexões sobre o exílio e outros ensaios. Trad. Pedro Maia Soares. São Paulo: Companhia das Letras, 2003.

TODOROV, Tzevetan. O homem desenraizado. Trad. Christina Cabo. Rio de Janeiro: Record, 1999. 
R. F. Faqueri; D.A. P.Zaratin

Imaginários do(s) deslocamento(s) na contemporaneidade: representações dos sujeitos em trânsito. 